\title{
EL PLIEGO DE CONDICIONES EN LA CONTRATACIÓN ESTATAL: RESPONSABILIDAD DEL ESTADO DERIVADA DEL ACTO DE ADJUDICACIÓN DEL CONTRATO SUSTENTADO EN CLAUSULAS AMBIGUAS.
}

The terms of conditions in the state contracting: Responsibility of the state derived from the award of the contract awarded in ambigue clauses.

Guillermo A. Bermúdez Salazar ${ }^{1}$

\section{RESUMEN}

Este artículo analiza el alcance de los pliegos de condiciones en la contratación pública colombiana teniendo en cuenta su grado de coercitividad y explora sobre la edificación de la responsabilidad de la administración pública de cara a los oferentes en los casos en que los pliegos hayan sido elaborados de manera incompleta, ambigua o confusa que conduzcan a interpretaciones o decisiones subjetivas.

Palabras claves: Contratación Estatal, Pliego de Condiciones, Responsabilidad de la Administración, Acto de Adjudicación del Contrato, Selección Objetiva, Modalidades de Selección.

\begin{abstract}
This article analyzes the scope of the specifications in the Colombian government procurement considering their degree of coercivity and explore on building the accountability of public administration in the face of bidders in cases where the statements have been prepared in incomplete, ambiguous or confusing ways that lead to interpretations or decisions subjective.
\end{abstract}

Keywords: State Contract, Specifications, Management's Responsibility, Act of Award, Objective Selection, Method of Selection.

\footnotetext{
${ }^{1}$ Abogado especialista en Derecho Administrativo de la Universidad Libre, asesor en contratación estatal, en asuntos disciplinarios y fiscales, en responsabilidad contractual, extracontractual, civil y del estado en asuntos electorales. ORCID ID: https:// orcid.org/0000-0001-7747-6814 E-mail: gbermudezsalazar@gmail.com
} 


\section{i. INTRODUCCIÓN.}

El pliego de condiciones es dentro de los documentos previos a la firma del contrato, el más importante; es la actuación administrativa fundamental y prevalente en los procesos de selección de contratistas, a tal grado que en ocasiones prevalece sobre el contenido del contrato cuando existe una eventual diferencia entre uno y otro ${ }^{2}$ hace parte integral del mismo ${ }^{3}$ (Consejo de Estado Rad: 33795, 2010; Rad: 15666, 2011), establece el marco de su ejecución y delimita su eventual modificación ${ }^{4} / 5$. (Gonzales, 2010; Camacho, 1993)

La naturaleza del pliego, considerado como un acto administrativo de carácter general ${ }^{6}$, la facultad discrecional de la administración al momento de su elaboración y las consecuencias jurídicas que a título de responsabilidad se puedan desprender, son sin duda temas de gran interés en materia contractual, sobre todo si se toma en cuenta los acontecimientos de corrupción que con frecuencia suceden en la contratación con entidades públicas. No es un secreto que una de las formas para direccionar los procesos de selección a favor de uno de los proponentes es a través de la manipulación de los pliego de condiciones, estableciéndose en ellos, o bien reglas que aunque no tienen relación directa con la evaluación de las ofertas el incumplimiento de una de ella trae como consecuencia la disminución del puntaje e incluso su rechazo, o estableciéndose clausulas en las que se muestra un claro direccionamiento del proceso y/o modalidad de selección de contratista ${ }^{7}$ en favor de uno de los oferentes.

Ante esto, este artículo busca en primera instancia dar una respuesta a la pregunta: ¿Cuál es el alcance del pliego de condiciones en la Contratación Estatal?, para así luego explorar sobre la forma

\footnotetext{
${ }^{2}$ Consejo de Estado. Sala de lo Contencioso Administrativo. Sección Tercera. Consejera Ponente: Ruth Stella Correa Palacio. Sentencia del 19 de julio de 2.010. Expediente: 33795 .

${ }^{3}$ Consejo de Estado. Sala de lo Contencioso Administrativo. Sección Tercera. Consejero Ponente: Danilo Rojas Betancourt. Sentencia del 10 de marzo de 2011. Expediente: 15666.

${ }^{4}$ GONZALES LOPEZ, Edgar. "El pliego de condiciones en la contratación estatal. La reforma consagrada en la ley 1150 de 2007 y sus decretos reglamentarios." Universidad Externado de Colombia. 2.010.

${ }^{5}$ MATAllanA CAMACHO, E. (2013). Manual de Contratación de la Administración Pública. Reforma de la ley 80 de 1993. Bogotá D.C.: Universidad Externado de Colombia.

${ }^{6}$ Consejo de Estado. Sala de lo Contencioso Administrativo. Sección Tercera. Consejero Ponente: Jaime Orlando Santofimio Gamboa. Sentencia del 2.012 .

${ }^{7}$ La revista Cambio del 22 de enero de 2009 presentó un informe sobre las prácticas de corrupción más comunes en contratación estatal que luego sería reinsertada por Matellana Camacho en su obra Manual de Contratación de la Administración Pública entre las que se destacan, entre otras, las (i) licitaciones express; (ii) el carrusel; (iii) el "pitufeo" de contratos; (iv) proponentes suicidas y (v) las zancadillas, todas ellas, a mi manera de ver, evitables precisamente con la elaboración adecuada y seria de los pliegos de condiciones de conformidad a la constitución y la ley. Así las cosas, teniendo en cuenta que día a día nacen nuevas formas de manipulación de los procesos de selección de contratistas, entre ellas la manipulación de los pliegos de condiciones estableciendo cláusulas que benefician a uno solo de los oferentes en desmedro de los intereses de los demás y como consecuencia, de los principios orientadores de la contratación administrativa, se debe avanzar igualmente en las herramientas que persistan en la lucha contra esos sistemas de corrupción.

Si se observa con claridad las denominadas prácticas de corrupción anteriormente mencionadas, puede verse que las mismas no son más que el producto de la manipulación de las cláusulas de los pliegos de condiciones, en beneficio como ya se dijo, de un solo proponente, cláusulas que al ser manipuladas por algunos funcionarios públicos para los fines ya señalados, se encuentran irremediablemente en oposición del principio de selección objetiva.
} 
en que se estructura la responsabilidad de la administración pública precisamente cuando ésta toma decisiones sustentadas en cláusulas ambiguas o confusas del pliego y que conducen a interpretaciones subjetivas. Nace así el problema cuando la descalificación o rechazo de la oferta se decide, si bien amparado en los parámetros establecidos en el pliego de condiciones, pero, estando dichos parámetros viciados por desconocer de manera grosera y evidente el principio de selección objetiva que debe regular toda la actividad precontractual de la administración.

\section{ii. EL PLIEGO DE CONDICIONES.}

\section{a. Naturaleza}

El Consejo de Estado en sentencia identificada con el número de expediente: 32871, ha tomado posición sobre las diversas teorías que intentan explicar la naturaleza jurídica del pliego de condiciones (Gonzáles, 2010), ya sea como un acto unilateral de la administración, como reglamento; o bien advirtiendo su carácter contractual, o de naturaleza mixta, asumiendo en primera instancia esta última tesis entendiendo que una vez adjudicado, el proceso muta y se incorpora en su parte pertinente, de tal manera que terminada la etapa precontractual se convierte en una cláusula del contrato.

Sin embargo, algunos tratadistas (Gonzáles, 2010) tanto en Colombia como en Derecho Comparado (García, 2010), consideran al pliego de condiciones como un acto administrativo, argumentando que no deja de serlo porque el proceso de selección del contratista termine satisfactoriamente con el acto de adjudicación y con el perfeccionamiento del contrato (García, 2010), sobre todo cuando los efectos del pliego no culminan con la adjudicación, sino que se extiende más allá, pues rige también durante las etapas de celebración, ejecución y liquidación, lo que les permite concluir que en el evento en el que exista alguna diferencia entre el pliego y el contrato, el primero prevalece sobre el segundo.

Esta posición doctrinal de entender al pliego de condiciones como un acto administrativo, fue asumida por la jurisprudencia del Consejo de Estado en varias sentencias, en especial en la providencia del 19 de septiembre de 2.007 en donde se dijo que el pliego de condiciones "se trata de un verdadero acto administrativo, toda vez que es una manifestación unilateral, en este caso de una administración pública, que genera efectos ante terceros de manera independiente a la anuencia de estos". (Consejo de Estado, Exp: 26649, 2007)

Más recientemente, en la sentencia del 14 de febrero de 2.012, la Sección Tercera del Consejo de Estado fue más específica, en el sentido de entender al pliego de condiciones como un acto administrativo de carácter general. 
En dicha sentencia la sala dijo:

[...] Precisamente en cuanto a la naturaleza del Pliego de Condiciones como acto precontractual, esta Corporación ha mantenido su postura señalando que se trata de un acto administrativo de contenido general, es decir, una manifestación unilateral de la voluntad de la Administración que crea situaciones jurídicas generales, impersonales, abstractas y objetivas sujeto a control de legalidad por parte de la Jurisdicción de lo Contencioso Administrativa mediante la acción de nulidad [...]. (Consejo de Estado, Exp:38924,2012)

Pese a lo expuesto por la doctrina nacional y parte dela doctrina extranjera, así como la jurisprudencia del Consejo de Estado, al menos en nuestro país, el pliego de condiciones es el documento precontractual que rige y disciplina el procedimiento para la selección del contratista, hace parte integral del contrato, establece el marco de su ejecución, delimita su eventual modificación y el termino para la liquidación del contrato, y por lo tanto su naturaleza jurídica debería estructurarse sobre su naturaleza contractual y no sobre la teoría del acto administrativo. En efecto, la Ley y su reglamento, no le han otorgado al pliego de condiciones la calidad única de acto y por el contario lo ha entendido en su expresión más sencilla, como lo es la de documento previo del contrato ${ }^{8}$, sin que esto signifique restarle importancia como ya se ha expuesto.

Por otra parte, no es necesario darle al pliego de condiciones la categoría de acto administrativo de carácter general con el objeto de justificar las razones por las cuales el mismo debe reglar el procedimiento para la selección del contratista, prevalecer sobre el contenido del contrato cuando exista diferencia entre uno y otro, establecer el marco de su ejecución o delimitar su eventual modificación, pues aquellas pueden resultar más sencillas y obvias, toda vez que en el pliego de condiciones se debe establecer entre otros puntos9: (i) la descripción técnica, detallada y completa del bien o servicio objeto del contrato, (ii) la modalidad del proceso de selección, (iii) los criterios de selección, incluyendo los factores de desempate y los incentivos si ello fuera posible, (iv) las condiciones de costo y/o calidad que se deben tener en cuenta para la selección objetiva del contratista; (v) las reglas para la presentación de las ofertas, su evaluación y posterior adjudicación, así como sus causales de rechazo, (vi) El valor del contrato, el plazo, y la determinación del anticipo si hubiera lugar, (vii) los términos, condiciones y minuta del contrato y (viii) el cronograma, presupuestos a los cuales debe ajustarse la propuesta, lo que significa en principio una aceptación tácita del contenido por parte de los oferentes.

\footnotetext{
${ }^{8} \mathrm{Al}$ tenor de lo dispuesto en el título II del decreto 1510 de julio $17 \mathrm{de} 2.013$ los estudios y documentos previos, el proyecto de pliego de condiciones y el pliego son documentos del proceso de contratación, situación que igualmente se evidencia cuando se advierte que los interesados pueden hacer observaciones al proyecto del pliego de condiciones dentro de los términos taxativamente señalados en búsqueda de su fortalecimiento, y al igual cuando se establece que el acto administrativo de apertura del proceso de selección del contratista debe establecer el lugar físico o electrónico en el que se pueda consultar y retirar los pliegos de condiciones.

${ }^{9}$ Decreto 1510 de 2013. Art. 22.
} 
En este orden de ideas, se recuerda que por mandato legal las propuestas deben referirse y sujetarse a cada uno de los puntos contenidos en el pliego de condiciones, y por lo tanto la correspondiente evaluación y la selección objetiva del contratista debe sujetarse a las mismas reglas y condiciones establecidas en el pliego.

Como se observa, desde el momento de la publicación del pliego de condiciones e incluso del proyecto de pliego, los oferentes conocen y detallan aspectos esenciales tanto del procedimiento para la selección del contratista como del contrato mismo, aspectos que los oferentes con la presentación de sus propuestas, aceptan y se atienen, y a los que además debe sujetarse la administración en su tarea de evaluar las ofertas y adjudicar el contrato.

Dicha comprensión deviene como es lógico de las reglas y principios constitucionales que rigen las actuaciones administrativas, así como las actuaciones de los particulares frente a la administración, pues no suena lógico que luego de haber sido la propia administración la encargada de detallar la necesidad para contratar, el presupuesto estimado y con ello el objeto del contrato, cambie sin causa justificada tales razonamientos. En el art. 83 de la Constitución Política se dice que las actuaciones de los particulares y de la administración deberán ceñirse a los postulados de la buena fe, lo que constituye en nuestro caso la fuente esencial de la obligatoriedad del pliego, al igual que otros principios que rigen las actuaciones de la administración pública, como lo son el de legalidad, igualdad y transparencia.

Incluso, el propio Consejo de Estado al explicar el principio contractual de sujeción estricta al pliego de condiciones, en sentencia del 19 de julio de 2001 lo definió como un principio fundamental del proceso licitatorio, que desarrolla la objetividad connatural a este procedimiento, en consideración a que el pliego es fuente principal de los derechos y obligaciones de la administración y de los proponentes (Consejo de Estado, Sent: 12037, 2001), respetando de contera el principio de libre concurrencia ${ }^{10}$ y el de la igualdad entre los proponentes ${ }^{11} \mathrm{y}$ en los cuales se soportan las garantías e importancia del pliego de condiciones.

De otra parte, en derecho comparado, más exactamente en el derecho español, se regulan los pliegos de condiciones generales, los pliegos de condiciones particulares y los pliegos de prescripciones técnicas como elementos normativos que buscan unificar los criterios y contenidos

\footnotetext{
${ }^{10}$ La libre concurrencia permite el acceso al proceso licitatorio de todas las personas o sujetos de derecho interesados en contratar con el Estado, mediante la adecuada publicidad de los actos previos o del llamado a licitar. Es un principio relativo, no absoluto o irrestricto, porque el interés público impone limitaciones de concurrencia relativas, entre otras, a la naturaleza del contrato y a la capacidad e idoneidad del oferente.

${ }^{11}$ La igualdad de los licitadores, es un presupuesto fundamental que garantiza la selección objetiva y desarrolla el principio de transparencia que orienta la contratación estatal, se traduce en la identidad de oportunidades dispuesta para los sujetos interesados en contratar con la Administración
} 
que presentan las diversas administraciones, nacionales o territoriales (Gonzáles, 2010), para los cuales debe tenerse en cuenta que el pliego de condiciones generales tiene vocación de permanencia, mientras que los pliegos de condiciones particulares y de prescripciones técnicas, solo son concebidos para un contrato especifico, marco conceptual que se asemeja en la doctrina española, francesa e italiana y en las que se sustentan sobre su naturaleza contractual. (Ariño, 2007)

A pesar de lo expuesto por el Consejo de Estado en las sentencias citadas, así como lo sostenido por parte de la doctrina, en Colombia no existe disposición normativa alguna que regule las categorías de pliego que por el contrario sí existen en derecho comparado, y por lo tanto no es posible sostener en el tiempo la tesis del pliego de condiciones como un acto administrativo de contenido general, dando paso a la posición doctrinal que subraya su condición mixta con mayor inclinación hacia su contenido contractual.

En efecto, en consideración a la regulación existente en Colombia a cerca del pliego de condiciones y dada la discrecionalidad administrativa que lo rodea, se asemeja mucho más a los pliegos de condiciones particulares y de prescripciones técnicas del derecho español, el cual, tal y como de antemano ha sido objeto de señalamiento, es concebido para un contrato especifico, y que la doctrina ha venido entendiendo a partir de su doble naturaleza jurídica, es decir, entendido inicialmente como un acto administrativo que luego de terminar de manera exitosa el proceso de selección, muta o se transforma en una cláusula del contrato ${ }^{12} / 13$.

Llevada a la práctica la concepción del pliego de condiciones particulares concebido en el derecho español, comparte estrecha relación con la forma del pliego en nuestro ordenamiento jurídico, y con el cual, comparte igualmente su naturaleza jurídica, razón por la cual exalto la condición mixta del pliego de condiciones.

\footnotetext{
${ }^{12}$ Sobre todo el contenido y la naturaleza de los pliegos de cláusulas administrativas particulares puede consultarse RAMÓN PARADA VAZQUES. Derecho Administrativo, T. I, Madrid, Marcial Pons, 1.995; EDUARDO GARCÍA DE ENTERRÍA y TOMAS RAMÓN FERNANDEZ RODRÍGUEZ. Curso de Derecho Administrativo, T. I Madrid, Civitas, 1989 (reimpresión 1.991); JUAN ALFONSO SANTAMARÍA PASTOR. Principios de derecho administrativo, Madrid, Centro de Estudios Ramón Areces, 1.994. Sobre las diferentes teorías con relación a la naturaleza contractual o reglamentaria y/o normativa de los pliego de condiciones particulares y su trato en la doctrina española, dividida al respecto; sobre la doctrina francesa, en especial sobre la concepción del derecho público, que también recoge estas dos posiciones, y sobre la doctrina italiana que los considera en forma prevalente de naturaleza contractual, puede verse CARLOS AYMERICH CANO. "acerca de la naturaleza normativa de los pliegos de cláusulas administrativas particulares", en FRANCISCO SOSA WAGNER (Coor). El derecho administrativo en el umbral del siglo XXI, homenaje al profesor D. RAMÓN MARTÍN MATEO, t. I, Madrid, Tirant Lo Blanch, 2.000.

${ }^{13}$ El pliego de cláusulas administrativas particulares en España, ha sido considerado por una parte de la doctrina como un acto administrativo de contenido general que una vez perfeccionado el contrato, se convierte en contenido del negocio celebrado, al ser expresamente aceptado por los proponentes y en especial por el adjudicatario. Cómo crítica de esta postura se tiene la de CARLOS AYMERICH CANO. "acerca de la naturaleza normativa de los pliegos de cláusulas administrativas particulares", en FRANCISCO SOSA WAGNER (Coor). El derecho administrativo en el umbral del siglo XXI, homenaje al profesor D. RAMÓN MARTÍN MATEO, t. I, Madrid, Tirant Lo Blanch, 2.000, tomado de Edgar Gonzales López. El pliego de condiciones en la contratación estatal. Op. Cit.
} 
Incluso, el Tribunal Supremo Español en sentencia que data del 22 de noviembre de 1985 (Ar. 1996/481), se refiere al carácter contractual de todos los pliegos, como un auténtico bloque normativo que constituye ley para las partes, en que quedan sujetos, tanto la administración como los particulares, y que no pueden ser interpretados, extrayendo de su contexto, las diferentes cláusulas sino en forma integral apoyándose las unas en las otras. (Gonzales, 2010)

Así las cosas, se puede sostener que el pliego de condiciones como un documento precontractual o previo al contrato en el cual se consignan la reglas que rigen el procedimiento y la selección del contratista, reglas que iluminadas por los principios orientadores de la administración pública y de la contratación estatal, deben ser objetivas y justas, dando de paso la oportunidad de participar en igualdad de condiciones a los posibles oferentes y al cual deberán sujetarse las ofertas; motivo por el cual se entiende que existiendo alguna diferencia entre el pliego y el contrato, el primero prevalece sobre el segundo; y que luego de culminar el proceso de selección de contratistas de manera exitosa, muta o se transforma en una cláusula del contrato.

No obstante lo anterior, lo cierto es que en la actualidad la jurisprudencia del Consejo de Estado, ha entendido al pliego como un acto administrativo de carácter general en la medida que crea situaciones jurídicas generales, abstractas e impersonales y por lo tanto susceptible de impugnación judicial ante lo contencioso administrativo en ejercicio de la acción de simple nulidad, y en el que además se consignan la reglas que rigen el procedimiento y la selección del contratista, además de que independientemente de la tesis sobre la naturaleza normativa, contractual, o mixta del pliego de condiciones, lo cierto es que sus efectos trascienden el proceso de selección y se extienden hasta la terminación de todas las obligaciones contractuales.

\section{b. Interpretación de las cláusulas del pliego de condiciones.}

Entendido que el pliego de condiciones es el documento precontractual que rige y disciplina el procedimiento de selección del contratista y que delimita el contenido y alcance del contrato, por supuesto sin dejar de lado la naturaleza de acto administrativo predicada por el Consejo de Estado y parte de la doctrina, toda propuesta que deba ser presentada por los particulares a miras de ser beneficiarios con la adjudicación del respectivo contrato, debe cumplir con los términos, referencias y condiciones establecidas en el pliego ${ }^{14}$.

Así las cosas, se debe empezar diciendo que la interpretación del pliego de condiciones solo es válida, o mejor, solo procede para definir su aplicación a circunstancias que no se encuentren

${ }^{14}$ Ley 80 de 1993, art. 30 núm. 6. Las propuestas deben referirse y sujetarse a todos y cada uno de los puntos contenidos en el pliego de condiciones o términos de referencia. Los proponentes pueden presentar alternativas y excepciones técnicas o económicas siempre y cuando ellas nos signifiquen condicionamientos para la adjudicación. - Expresión subrayada derogada por la Ley 1150 de 2.007. 
expresamente reguladas por él, es decir, que su interpretación solo tiene cabida de manera excepcional. Así lo definió la Sección Tercera de la Sala de lo Contencioso Administrativo del Consejo de Estado en la sentencia del 29 de enero de 2.004.

En dicha sentencia la sala enseñó:

(...). Conviene igualmente advertir que, so pretexto de interpretar el pliego, no resulta procedente alterar o inaplicar sus condiciones, porque con ello se violarían los principios que rigen la selección del contratista. Se tiene entonces que procede la interpretación del pliego para definir su aplicación a circunstancias que no se regularon expresamente en él, a cuyo efecto debe definirse la naturaleza de la disposición -sustancial o de trámite - y buscar el sentido "que más se acomode a la justicia y la conveniencia pública. (Consejo de Estado, Sent: 13416, 2004)

Se precisa que a la luz de la sentencia del Consejo de Estado, con la interpretación del pliego de condiciones en las circunstancias ya explicadas se debe velar por buscar el sentido más justo y en el que prevalezca el interés general, o como lo dice la misma sentencia, que la interpretación que se haga sea aquella que más se acomode a la justicia y a la conveniencia pública, dos supuestos que limitan y dirigen la fórmula de interpretación del pliego que resulte aplicable.

Más recientemente, el Consejo de Estado en sentencia del 29 de agosto de 2.012 estableció una posición más amplia que adiciona o complementa la visión anteriormente mencionada, en la cual señaló que los pliegos de condiciones deben ser interpretados en función de las diferentes partes que lo conforman, sin separar o aislar una de ellas de su conjunto. (Consejo de Estado, Sent: 21077, 2012)

\section{c. Discrecionalidad y Configuración del Pliego de Condiciones}

Como bien se dijo anteriormente, el decreto 1510 de 2013 establece los requisitos mínimos que debe contener el pliego de condiciones. La existencia de la discrecionalidad administrativa en la configuración del pliego de condiciones, obedece a su parte casuística, pues si bien se definen unos parámetros mínimos comunes a todos los pliegos de condiciones, no se preestablece un formato común de elaboración de pliegos para cada uno de los contratos que puede celebrar el Estado.

La Sección Tercera de la Sala de lo Contencioso Administrativo del Consejo de Estado en sentencia del 30 de julio de 2.008 con ponencia de Mauricio Fajardo Gómez, señala:

(...) la configuración de pliegos de condiciones constituye un paradigmático ejemplo útil a efecto de ilustrar la dinámica que envuelve la concepción que de la discrecionalidad administrativa ha venido prohijando la Sala, partiendo de diferenciar las denominadas definiciones "materiales" o "positivas" de dicha figura, de las catalogadas como "formales" o "negativas" de la misma. Las primeras consideran que la discrecionalidad opera en circunstancias en las cuales el interés 
general, para el caso concreto, no se encuentra exhaustivamente precisado por la ley $\square$ lo cual evidentemente ocurre tratándose de las referidas normas que regulan el contenido mínimo de los pliegos de condiciones $\square$, de suerte que la discrecionalidad surge como autorización que se confiere $\square$ expresa o implícitamente $\square$ a la Administración para que, previa ponderación de todos los hechos, intereses, derechos o principios jurídicos comprometidos en el caso concreto, encuentre una solución para el mismo intentando «elegir la medida más adecuada para la satisfacción del interés público: éste se encuentra legalmente definido y fijado, pero no casuísticamente predeterminado, tarea para la que se confiere libertad al órgano actuante otorgándole un poder discrecional». (Consejo de Estado, Exp: 23003, 2008)

Ahora bien, como quiera que discrecionalidad no signifique arbitrariedad, aquella debe estar orientada por los principios rectores de la contratación estatal, como lo son los de economía, transparencia, igualdad y selección objetiva, en el sentido de identificar como contenido del pliego, cláusulas que permitan la evaluación transparente de las propuestas con la correspondiente selección objetiva de la oferta más favorable.

\section{d. Cláusulas Ambiguas y ajuste de la oferta al contenido del pliego.}

La Administración Pública es la encargada de efectuar la planeación que precede a la apertura de los procesos de contratación y en consecuencia, no sólo le corresponde realizar los estudios, análisis y cálculos previos que se requieran, sino también la elaboración del respectivo pliego de condiciones y del futuro contrato. Sobre ella pesa una carga de corrección, claridad y precisión en la elaboración y redacción de tales documentos de contratación, que se traduce en el deber de soportar las consecuencias que se deriven de la buena o mala confección de los mismos, de manera que los pasajes oscuros, confusos, incompletos y ambigüos que se encuentren en ellos, deben ser interpretados en su contra, precisamente por haber sido quien los elaboró y quien falló en esa tarea. (Consejo de Estado, Exp: 15666, 2011)

La carga de la claridad del pliego de condiciones recae sobre la administración pública, pues gozando esta de un grado de discrecionalidad para la elaboración del pliego, es ella a quien compromete la claridad del documento guía y estructurador del procedimiento de selección de contratista; igualmente, debe advertirse que las cláusulas ambiguas o confusas del pliego de condiciones deben interpretarse en contra de la administración. (Gonzales, 2010)

\section{iii. RESPONSABILIDAD DEL ESTADO DERIVADA DEL ACTO DE ADJUDICACIÓN DEL CONTRATO.}

\section{a. Responsabilidad precontractual del Estado.}

A partir de 1.991, la responsabilidad contractual del Estado debe ser estudiada sin anfibología desde la perspectiva de la dióptrica constitucional con apoyatura filosófica y normativa en el art. 90 superior, en el cual se señala un modelo de Estado instituido al que se le puede imputar responsabilidad 
por los daños antijurídicos que causen sus funcionarios por acción u omisión ${ }^{15}$.

El Estado, puede ser responsable de los daños antijurídicos que se causen durante cada una de las etapas contractuales, como las que son la etapa precontractual, contractual y post-contractual del respectivo negocio jurídico.

Atendiendo las etapas del contrato anteriormente mencionado, es claro que durante la etapa contractual le son aplicables las teorías de incumplimiento, cumplimiento tardío y cumplimiento defectuoso comúnmente aplicadas en la doctrina civilista, además del resto teorías que han venido siendo desarrolladas por ésta rama del derecho, cambiando por supuesto algunos aspectos atendiendo a los finos requerimientos y condiciones que estructura la contratación del Estado. Se señala entonces que durante esta etapa, como es lógico, son fundamento de responsabilidad los actos de ejecución del contrato y demás hechos y causas ocurridas durante esta etapa.

En la etapa post-contractual, se compromete la responsabilidad de los co-contratantes durante los actos de liquidación del contrato, y en ello, los reconocimientos mutuos a los que hubiere lugar.

Por último, y siendo de mayor interés en atención al tema sobre el cual se estructura este artículo, se encuentra la responsabilidad del estado durante la etapa precontractual, que inicia desde la publicación del pliego de condiciones hasta el acto de adjudicación del contrato, el cual en la mayoría de los casos, salvo algunas excepciones, debe entenderse como el acto administrativo definitivo, y por lo tanto sujeto a impugnación judicial a través de los medio de control de Nulidad y Nulidad y Restablecimiento del Derecho, e incluso por medio del medio de control de Controversias Contractuales, siempre y cuando se fundamente el vicio de nulidad del acto de adjudicación como un vicio de nulidad absoluta del contrato con las especiales implicaciones procesales y jurídicas que en adelante se explican.

Sin embargo, para efectos de este trabajo resulta de especial interés la responsabilidad de la administración pública derivada de hechos y causas ocurridas durante la etapa precontractual y que por lo tanto, presta especial interés las causas especificas del pliego de condiciones, la propuesta y el acto de adjudicación, limitándose a la variante especifica del tema en estudio.

El Consejo de Estado en sentencia del 7 de junio de 2001, en cuanto al tema de la responsabilidad

\footnotetext{
${ }^{15}$ Constitución Política de 1.991. art. 90: El Estado responderá patrimonialmente por los daños antijurídicos que le sean imputables, causados por la acción o la omisión de las autoridades públicas.

En el evento de ser condenado el Estado a la reparación patrimonial de uno de tales daños, que haya sido consecuencia de la conducta dolosa o gravemente culposa de un agente suyo, aquél deberá repetir contra éste.
} 
precontractual del Estado, por oposición a la responsabilidad precontractual en las relaciones de los particulares, señaló ${ }^{16}$ :

Las fuentes que enriquecen la responsabilidad precontractual en el ámbito civil y mercantil no puedan traerse al ámbito de la contratación estatal en toda su extensión porque allí rige el principio de la solemnidad, en tanto el perfeccionamiento del contrato está condicionado a que el acuerdo de voluntades sobre el objeto y la contraprestación se eleve a escrito (art. 41 ley 80 de 1993). Se configura la responsabilidad precontractual o por daño in contrahendo cuando la administración pública o los proponentes sufren un daño antijurídico como consecuencia de una acción o omisión atribuible a la otra parte durante la etapa de la formación de la voluntad, que determina la imposibilidad de seleccionar el proponente, o la adjudicación irregular de la licitación, o la falta de perfeccionamiento del contrato, caso en el cual la administración compromete su responsabilidad civil, como también la compromete el proponente que retira su oferta o que se niega a celebrar el contrato en las condiciones propuestas y aceptadas. En el ámbito del derecho administrativo la imputación de responsabilidad por los daños causados en la etapa precontractual no se hace con fundamento en la culpa, ni en el riesgo ni en el enriquecimiento injusto, o la reciprocidad de prestaciones del contrato bilateral, sino en los principios de la buena fe y de legalidad. En la etapa de formación de la voluntad contractual las partes deben obrar de buena fe en la preparación del contrato, en el procedimiento de selección y en la fase de perfeccionamiento del mismo, no sólo porque así lo manda la Constitución (art. 83) sino porque es principio general que domina las relaciones jurídicas bilaterales como dan cuenta los artículos 1603 del Código Civil y 863 y 871 del C. de Comercio. Ligado a la buena fe que se deben las partes en la formación de la voluntad para la celebración del contrato está el principio de legalidad, según el cual las partes deben encauzar la formación de esa voluntad dentro de las reglas de la gestión contractual pública prescritas por la ley. Con fundamento en este principio la administración en la gestación de sus contratos debe respetar la ley en su sentido formal y material, como también todas las fuentes del ordenamiento jurídico, en particular las especiales del derecho administrativo, sus reglamentos y los pliegos de condiciones y quienes tengan interés en formalizar compromisos con ella deben sujetarse a esos reglamentos y condiciones especiales de contratación. En otras palabras, la administración para seleccionar a sus contratistas debe sujetarse a un procedimiento reglado como lo es el de la licitación y los oferentes como contrapartida deben someterse a ese procedimiento y cuando sea frustrado su interés de contratar con el Estado, tendrán la carga de probar que se sujetaron a las exigencias legales y reglamentarias (Consejo de Estado, Exp. 13405, 2001)

\footnotetext{
${ }^{16}$ Consejo de Estado. Sala de lo Contencioso Administrativo. Sección Tercera. Consejero Ponente: Ricardo Hoyos Duque. Sentencia del 7 de junio de 2.001. Exp. 13405. - En esta misma sentencia, la sala en relación a la responsabilidad precontractual de los particulares dijo que "de la responsabilidad precontractual en el derecho privado se habla para referirse la responsabilidad en que incurren las partes por su conducta en la etapa anterior a la celebración de un contrato. "Para que surja el problema hay que suponer necesariamente dos personas que se relacionan con el objeto de celebrar un contrato. Se encuentran en la época de las negociaciones o período precontractual. Pero las negociaciones no tienen éxito y el acuerdo no se celebra. Puede suceder que este fracaso cause algún perjuicio al uno o al otro de los contratantes frustrados." El derecho colombiano en la legislación comercial se ocupa del estudio de la etapa anterior al perfeccionamiento del contrato, en tanto regula separadamente las declaraciones de voluntad unilaterales que ocurren antes del perfeccionamiento del negocio (el contrato), las cuales son autónomas y como tales generan responsabilidad: se trata de la oferta y su aceptación. El art. 846 del Código de Comercio obliga a indemnizar los perjuicios que cause el oferente que se retracte de la oferta ya comunicada y de ahí que la norma la defina como irrevocable. En tanto la aceptación es el acto jurídico unilateral que proviene del destinatario de la oferta, si opta por aceptarla, toda vez que no está obligado a hacerlo. El hecho de repudiar la oferta o dejar pasar su término, no genera obligaciones para el destinatario; pero en ésta como en cualquier otra actividad precontractual, las partes intervinientes deben comportarse de acuerdo con el principio general de la buena fe (art. 863 C. de Co.), so pena de comprometer su responsabilidad. Se ha precisado por la doctrina y la jurisprudencia que las partes antes de hallarse definitivamente ligadas por un contrato, se sitúan en diferentes posiciones; en primer término, en las llamadas negociaciones preliminares, actos previos de acercamiento entre las partes que excluyen la posibilidad de un vínculo jurídico (una cita, una llamada telefónica, por ejemplo) para pasar a la etapa precontractual propiamente dicha que se inicia con la oferta. En derecho privado no tiene discusión que los tratos preliminares encaminados a la celebración de un contrato pueden generar responsabilidad para la parte que los incumpla, en la medida en que se vulnera el principio de la buena fe.
} 
La providencia transcrita señala los derroteros básicos a tener en encuentra en la estructuración de la responsabilidad precontractual del Estado y señala de contera algunos casos en los que la responsabilidad se mira transparente.

Como lo señalamos desde el principio de este artículo, la buena fe y la legalidad son el pilar fundamental y filosófico de la responsabilidad precontractual de la administración. En efecto, en el art. 83 de la Constitución Política se dice que las actuaciones de los particulares y de la administración deberán ceñirse a los postulados de la buena fe, lo que constituye en nuestro caso la fuente esencial de la obligatoriedad del pliego, al igual que otros principios que rigen las actuaciones de la administración pública, como lo son el de legalidad, igualdad y transparencia.

Este postulado de la buena fe aplicado a la contratación estatal en todas sus etapas, en especial a la etapa precontractual, y sobre todo teniendo en cuenta la posibilidad de los oferentes de realizar observaciones en la respectiva oportunidad con respecto a las cláusulas del pliego de condiciones ha dado lugar a diferencias de criterio sobre hasta dónde llega la responsabilidad del Estado, y hasta donde se vería trasladada dicha responsabilidad a los oferentes.

Sin duda, en la etapa precontractual, la responsabilidad de las partes, o mejor de la administración pública, se estructura sobre los principios de la buena fe y de la legalidad, y en general de los principios orientadores de la contratación pública, en especial sobre el principio de selección objetiva, y precisamente a partir del primero (buena fe), es que podemos hablar de la traslación de responsabilidad en cabeza de los oferentes, sin embargo la situación aquí planteada de ninguna manera puede ser entendida como la regla general, pero sí como excepción.

\section{b. Cláusulas ambiguas, oscuras o anfibológicas. Interpretación e Imputación.}

La libertad de configuración del pliego de condiciones como facultad discrecional de la administración dispone el marco teórico de la responsabilidad de la administración pública por su contenido, máxime cuando en virtud del principio de la carga de claridad del pliego, las cláusulas ambiguas, contradictorias, oscuras o anfibológicas deben ser interpretadas en contra de la administración.

En efecto, la administración dispone de libertad de valoración para la configuración del pliego de condiciones, que debe reglarse dentro de los principios de legalidad, planeación, economía y selección objetiva, y de acuerdo a los requerimientos técnicos y específicos que se exigen para cada mecanismo de selección de contratistas, y es precisamente por esta razón, que se ha señalado que la administración ejerce una facultad discrecional de configuración para ponderar los hechos, intereses, derechos y principios jurídicos comprometidos en un caso concreto y para una determinada 
solución. (Gonzales, 2010)

De acuerdo con Hugo Alberto Marín Hernández, calidades del proponente como la experiencia, capacidad financiera y organización, que pueden ser requisitos de rechazo de la oferta o de ponderación según la modalidad del proceso de selección, o el menor plazo en los procesos de licitación distintos de obra, o aspectos relacionados con el objeto y su descripción técnica, deben ser apreciados por la entidad contratante al momento de la elaboración del pliego de condiciones de la manera que mejor consulte los intereses y necesidades públicas, y conforme a los criterios razonables, objetivos y guiados por la máxima de proporcionalidad referentes al proceso de selección de contratista que se adelanta. (Marín, 2009)

Tal y como fue objeto de explicación, el grado de discrecionalidad con la que cuenta la administración para la configuración del pliego, lleva como consecuencia implícita la carga de claridad del documento orientador del proceso de selección del contratista, por lo que se repite, las cláusulas ambiguas, oscuras, contradictorias o anfibológicas deben ser interpretadas en contra de la administración sobre todo cuando la experiencia muestra que el proponente llega al proceso de selección del contratista e incluso a la suscripción del contrato, haciéndole venia a la filosofía que ilustra la categoría tipológica de los contratos de adhesión ${ }^{17}$.

Como se dijo, los potenciales oferentes en la etapa de actuación administrativa anterior a la etapa precontractual, o aun en la ejecución de esta, tienen la posibilidad de presentar observaciones sobre el contenido del proyecto de pliego de condiciones y del pliego, con la obligación consiguiente de la administración de dar respuesta a dichas observaciones de manera motivada, y en caso de ser procedentes, realizar las modificaciones al contenido del pliego de condiciones antes de ser presentadas las ofertas y dentro de los limites señalados por las fuentes del derecho.

Lo anterior, ha dado lugar a diferencias conceptuales sobre hasta dónde llega la responsabilidad de la administración de cara a los oferentes y hasta donde se traslada dicha responsabilidad en cabeza de los oferentes, en especial cuando se trata de cláusulas ambiguas, oscuras o anfibológicas, como si existiera algún tipo de saneamiento cuando en presencia de dichas cláusulas el oferente guardara silencio y no realizara ningún tipo de observaciones, y luego en la etapa de ejecución presentara la correspondiente reclamación, o se demandara la nulidad del acto de adjudicación del contrato con fundamento en dicha causa, lo que encuentra sustento en la teoría de los actos propios.

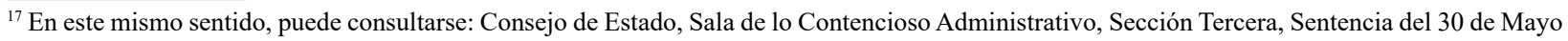
de 1.991. Consejero Ponente: Julio Cesar Uribe Acosta. Expediente 3.577. 
Como es lógico, en la contratación con entidades del Estado, debe considerarse los hechos específicos con miras a comprobar si el silencio del oferente en la etapa de observaciones puede ser entendido como una causal de exoneración de Responsabilidad del Estado, o si por el contrario, dicho silencio en ningún momento debe entenderse como causal de ausencia de responsabilidad.

No obstante, considero que es la administración la que está obligada a cumplir con el principio de planeación al momento de elaborar el pliego de condiciones y por lo tanto, es de su responsabilidad que las reglas en él consagradas sean claras y completas, por lo que en principio, no habría razón suficiente para trasladar la responsabilidad a los oferentes, ni tampoco hablarse de responsabilidad compartida, pues a la administración es a quien le compete la carga de la claridad y consistencia del pliego de condiciones.

Sostengo que en principio, por cuanto en algunas ocasiones, se podría sostener jurídicamente que el silencio del oferente, si bien no da lugar a la traslación de la responsabilidad, si le impediría que luego intentara iniciar las correspondientes reclamaciones con ocasión a la situación administrativa contemplada en el pliego y ante la cual guardó silencio, como es el caso de las ofertas presentadas guardando estrecha relación al presupuesto oficial, pero estando dicho presupuesto por debajo de los valores normales del mercado, los cuales, debieran ser medianamente conocidos por el oferente teniendo en cuenta el giro normal de sus negocios.

Por lo tanto, si el pliego de condiciones es incompleto, establece reglas subjetivas o equivocadas, especialmente en la evaluación y ponderación de las ofertas, habrá responsabilidad de la administración en virtud del principio de la carga de claridad del pliego de condiciones (Gonzales, 2010), o como explica Rodrigo Escobar Gil, será una responsabilidad que debe asumir la administración pública dada la carga de claridad que le es imputable, por lo que los errores contenidos en el pliego de condiciones que hayan dado origen a un error en el oferente, o a la adjudicación del contrato con fundamento en una interpretación subjetiva, son de su responsabilidad, y en ningún momento podrá endilgarse el riesgo al particular.(Escobar, 1999)

\section{c. El acto de adjudicación del contrato, la acción contenciosa de nulidad y restablecimiento del derecho y la inaplicación de cláusulas ilegales del pliego de condiciones.}

El acto de adjudicación del contrato en palabras del Consejo de Estado, supone -desde una faceta positiva- la selección y por lo mismo la aceptación de la oferta que se estima la más conveniente y favorable con arreglo a lo dispuesto en los pliegos de condiciones y -desde una faceta negativa- la no adjudicación a los otros proponentes. Sin embargo, conviene precisar que el acto de adjudicación, en tanto por él se acepta la oferta del oferente favorecido y se concluye el procedimiento licitatorio, 
en el derecho nacional aunque no perfecciona el vínculo jurídico en tratándose del contrato estatal, es presupuesto sine qua non para la ulterior celebración del respectivo contrato, como que crea la obligación tanto para la administración como para el adjudicatario de elevar a escrito el acuerdo de voluntades. De modo que la suscripción no es sino la formalización de la voluntad administrativa de la entidad licitante expresada a lo largo de ese proceso y de la del co-contratante que formuló la oferta seleccionada, en lo que Alessi llama "fase integrativa", con el fin de lograr el perfeccionamiento del contrato en los términos del artículo 41 de la Ley $80^{18}$.

Bajo esta perspectiva, el artículo 9 de la Ley 1150 de 2007 establece que el acto de adjudicación es irrevocable y obliga a la entidad y al adjudicatario. Así lo había reconocido, de antaño, la jurisprudencia de esta Corporación:

Los efectos de la adjudicación son bien conocidos, como que se ha afirmado constantemente que, desde que ella se comunica, surge entre adjudicatario y adjudicante una situación contentiva de mutuos derechos y obligaciones, y de la que el contrato no viene a ser sino la forma instrumental o el acto formal. (Consejo de Estado, Exp:1503, 1975)

Por manera que, el acto administrativo de adjudicación produce una serie de consecuencias jurídicas respecto de las partes intervinientes en el procedimiento: i) el derecho subjetivo del adjudicatario, como situación excluyente para contratar con el Estado; ii) deber jurídico correlativo del licitante de contratar con el adjudicatario; iii) mantenimiento inalterable de los pliegos de condiciones, entre otros, directamente entroncados con la celebración misma del negocio jurídico. En tal virtud, serán los oferentes no favorecidos así como la misma administración, quienes en realidad de verdad ostentan un interés legítimo para demandar el acto de adjudicación, en tanto podrían alegar que fueron privados injustamente del derecho a ser adjudicatarios, o se vieron afectados con la adjudicación, en orden a proteger un derecho subjetivo que se estima vulnerado por el acto demandado. (Consejo de Estado, Exp: 1503, 1975)

La selección del contratista, está sometida a los principios de transparencia, selección objetiva, igualdad y transparencia, por virtud de los cuales surgen, entre otras, la obligación de someter a todos los oferentes y sus propuestas a las mismas reglas del pliego de condiciones, reglas que como se ha sostenido, deben ser objetivas y justas. Se tiene por tanto que los principios de transparencia, igualdad y de selección objetiva, a que está sometida la selección del contratista, se desarrollan mediante la sujeción de la licitación pública a la ley y al pliego de condiciones, sin perjuicio de que éste último pueda interpretarse frente a situaciones no reguladas expresamente en él, y siempre ${ }^{18}$ Acerca de los efectos de la adjudicación, ver sentencia del Consejo de Estado, Sección Tercera, de enero 16 de 1975, exp. 1503, M.P. Gabriel
Rojas Arbeláez. 
que sus reglas no sean de aquellas que la doctrina y la jurisprudencia entiende como nulas de pleno derecho. (Consejo de Estado, Exp: 12037, 2001)

El Consejo de Estado en sentencia del 13 de junio de 2011 señaló que la acción procedente en contra del acto de adjudicación del contrato es la de nulidad y restablecimiento del derecho ${ }^{19}, \mathrm{y}$ presenciándose también la de controversias contractuales en la que se solicite la nulidad del contrato por ilicitud del acto de adjudicación del contrato, caso en el cual no hay lugar a indemnización. (Fandiño, 2014)

La prosperidad de la pretensión de nulidad del acto de adjudicación y de la consecuente condena a la indemnización de perjuicios derivada de la privación del derecho a ser adjudicatario, cualquiera que sea la razón que la sustenta, está condicionada a que el demandante demuestre:

i) que el acto de adjudicación es contrario al ordenamiento que rige la selección del contratista porque no contiene la escogencia de la mejor propuesta y ii) que se demuestre que, mediante el sometimiento estricto a las normas que rigen la escogencia del contratista, se deduce que el actor hizo la mejor propuesta. (Consejo de Estado, Exp: 15963,

Se tiene entonces que, como el procedimiento de selección del contratista está sometido, entre otros, a los principios de transparencia, selección objetiva e igualdad, las entidades deben someter sus actuaciones a lo dispuesto en la ley y en el correspondiente pliego de condiciones, como quiera que el Estado y los participantes están subordinados en idéntica forma a tales normas ${ }^{20}$.

Ahora bien, puede suceder que la ilegalidad del acto de adjudicación se derive de la ilegalidad de alguno de los requisitos previstos en el pliego, a cuyo efecto el juez de la adjudicación bien puede compararlos con el marco constitucional y legal que rige el ejercicio de dicha función administrativa y abstenerse de aplicarlos a la hora de verificar la evaluación de las propuestas, cuando los considere abiertamente ilegales. En efecto, la sección tercera del, Consejo de Estado, con apoyo en la ley, ha considerado que los requisitos abiertamente ilícitos del pliego de condiciones, son ineficaces y no deben tenerse en cuenta por el juez administrativo"21.

En sentencia del 21 de mayo de 2008, el Consejo de Estado procedió a declarar la nulidad del acto

\footnotetext{
${ }^{19}$ En relación con los antecedentes jurisprudenciales acerca de la acción idónea para demandar el acto de adjudicación de un contrato, ver sentencia del Consejo de Estado, Sección Tercera, de septiembre 19 de 2007, exp. 26649, Actor: Carolina Arango Uribe, Demandado: Instituto Nacional de Concesiones, M.P. Enrique Gil Botero. Así mismo, consultar las sentencias de la Corte Constitucional, C-1048 de 2001 y C-712 de 2005.

${ }^{20}$ Ver Sentencia proferida el 19 de septiembre de 1994. Expediente 8071; sentencias del 27 de marzo de 1992, expediente 6353, 11 de abril de 2002, expediente 12.294 y 19 de julio de Expediente 12.037;

${ }^{21}$ Sobre INAPLICACION DEL PLIEGO DE CONDICIONES POR ILEGALIDAD: sentencia 11192 proferida el 23 de abril de 1998; sentencia del 3 de mayo de 1999, Expediente 12.344, CP: Dr. Daniel Suárez Hernández; sentencia 15.235, del 24 de junio de 2004; Sentencia de 27 de noviembre de 2002. Exp. 13.792. Actor: Sociedad Henry Lozada Vélez y Cía Ltda. Demandado: INVICALI.
} 
de adjudicación del contrato mediante la inaplicación de un requisito del pliego que sea abiertamente ilegal.

En efecto, el Consejo de Estado, con apoyo en la ley, ha considerado que los requisitos abiertamente ilícitos del pliego de condiciones, son ineficaces y no deben tenerse en cuenta por el juez administrativo, al igual que aquellas que conllevan en forma implícita una valoración subjetiva. Así, en sentencia 11192 proferida el 23 de abril de 1998, explicó:

“.... la Sala entiende que no es permisible a la entidad contratante establecer en el pliego de condiciones, previsiones en virtud de las cuales la entidad se reserve 'el derecho de aceptar o no ofertas que no reúnan la totalidad de requisitos o que presenten defectos en forma (sic.), omisiones o errores significativos y aquéllas que no sean convenientes para la entidad', tal cual lo determinaron los pliegos de condiciones que gobernaron la licitación que ha originado el presente proceso, pues una cláusula con esos alcances riñe abiertamente con elementales principios aplicables al régimen de contratación estatal, por virtud de los cuales, no es permisible a los sujetos involucrados en el proceso de selección y particularmente a la entidad licitante 'reservarse derechos' de que carece y que no son de su resorte por corresponder a la competencia normativa del ordenamiento y no dispositiva de los particulares, como que por esa vía, la entidad podría eludir el cumplimiento de la ley pues claro resulta que las ofertas deben reunir la totalidad de los requisitos que se reputan esenciales como condición sine qua non para poder ser estudiadas y consideradas, de la misma manera que aquéllas que evidencien omisiones o errores significativos, tampoco son hábiles para su consideración, por lo cual,_dichas reservas, no pasan de ser cláusulas de estilo sin eficacia alguna, pues absurdo resultaría que frente a mandatos imperativos de orden público como aquél contenido en el art. 33 del anterior estatuto contractual o el preceptuado en el art. 29 de la ley 80 de 1993, ambos consagratorios del principio objetivo que ha de presidir la selección del contratista, pudiera la entidad contratante reservarse una inexistente discrecionalidad y arrogarse el poder sin fundamento legal de ninguna naturaleza de aceptar o no a su antojo las propuestas que contengan deficiencias graves o errores trascendentales y relevantes, pues esta materia es de orden público y el rigor que ha de presidir la consideración de las propuestas así como los parámetros de necesaria observancia están delimitados en la ley, la cual ha disciplinado los criterios objetivos de selección que en manera alguna pueden quedar librados al antojo de la entidad contratante.

Quizás por ello el actual estatuto contractual expresa e inequívocamente determinó que aquellas estipulaciones contenidas en los pliegos de condiciones o términos de referencia que contravengan las prescripciones contenidas en el art. 24 de la ley 80 de 1993 consagratorio del principio de la transparencia "serán ineficaces de pleno derecho", particularmente aquéllas que establezcan reglas de selección por fuera de la objetividad, claridad y justicia que debe manifestarse en los pliegos que gobiernan el proceso de selección.

La anterior precisión se hace en atención a la postura procesal asumida por el ente demandado quien a manera de defensa invocó frente a la controversia planteada la aplicación de dicha cláusula, que se reitera, en sentir de la Sala, es ineficaz de pleno derecho, esto es, sin necesidad de declaratoria jurisdiccional a propósito, no obstante que del análisis probatorio realizado en la presente providencia los cargos enderezados a la declaratoria de nulidad del acto de adjudicación no se abren paso por las razones expuestas anteriormente." (Se subraya)

Igual postura asumió la Sala en sentencia proferida el 3 de mayo de 1999 en la que explicó: 
"Es principio fundamental informador de la etapa de selección del contratista, el de garantizar la igualdad de los oferentes y por lo mismo bajo dicha óptica todas aquellas cláusulas que puedan comportar la vulneración de tal principio, son susceptibles de depuración, por parte del juez del contrato, como que la aplicación indiscriminada de aquellas, puede constituir la fuente de daños y perjuicios para cualquiera de los partícipes dentro del proceso de selección objetiva.

La administración no puede establecer criterios irrazonables que no consulten el interés general presente tanto en el proceso de selección como en la ejecución del contrato estatal, so pena de ineficacia de dichas cláusulas predispuestas ante casos de violación mayúscula del ordenamiento jurídico v. gr. contravención de norma de orden público o, de exponerse a un control riguroso de contenido por parte del juez del contrato, quien por vía de la cláusula general de buena fe o, bajo la óptica del principio de objetividad o de igualdad, puede corregir o ajustar el contenido de la cláusula, con el propósito de preservar la eficacia vinculante de la que ha sido predispuesta, garantizando así, en todo caso, la aplicación cabal de los principios informadores de la contratación estatal." (Consejo de Estado, Exp: 12.344, 1999)

Que fue reiterada, entre otras, en sentencia 15.235:

"De conformidad con lo expuesto precedentemente, el juez administrativo es competente para inaplicar el pliego de condiciones cuando encuentre que uno de sus preceptos viola la ley y es el sustento legal de cualquiera de las decisiones que tome la entidad contratante durante la actividad contractual y en él se fundamente el vicio de nulidad de aquéllas. (Consejo de Estado, Sent: $15.235,2004)$

La mal llamada excepción de ilegalidad (Corte Constitucional, C-037, 2000) se fundamenta en 'la necesidad de inaplicar aquellas disposiciones que por ser contrarias a aquellas otras de las cuales se derivan su validez, dan lugar a la ruptura de la armonía normativa. Así, aunque la Constitución no la contemple expresamente... resulta obvio que las disposiciones superiores que consagran rangos y jerarquías normativas, deben ser implementadas mediante mecanismos, que las hagan efectivas, y que, en ese sentido, la posibilidad de inaplicar las normas de inferior rango que resulten contradictorias a aquellas otras a las cuales por disposición constitucional deben subordinarse, es decir, la excepción de ilegalidad, resulta acorde con la Constitución (Corte Constitucional, C-037, 2000)' Dicha facultad está reservada a la jurisdicción contenciosa administrativa, tal como fue reconocido por la Corte Constitucional $(\ldots)^{22}$

La inaplicación, concretamente de las disposiciones del pliego de condiciones, encuentra sustento, además, en la ley 80 de 1993, la cual en el inciso segundo del literal f. del numeral $5 \mathrm{del}$ art. 24, sanciona con la ineficacia, de pleno derecho, las estipulaciones de los pliegos de condiciones o términos de referencia y de los contratos que contravengan lo dispuesto en ese numeral. (Consejo de Estado, Exp: 13792, 2002)

Así las cosas, el Juez al momento de la evaluación de las ofertas, debe excluir la cláusula del pliego de condiciones que determine la subjetividad de la elección de la oferta en el acto de adjudicación del contrato, y de esa manera, indicar la selección objetiva del contratista.

\footnotetext{
${ }^{22}$ La ineficacia, de pleno derecho, en los términos que establece la ley 80 de 1993, permite concluir que no siempre habrá necesidad de demandar directamente el pliego de condiciones. Basta que en él se estipulen disposiciones que contravengan lo que la ley señala para que se le fulmine esa sanción.
} 
Sin embargo, se debe precisar que en casos como el que se estudia, el demandante ostenta la carga probatoria de demostrar dos aspectos esencialmente relevantes:

i) que el acto de adjudicación es contrario al ordenamiento que rige la selección del contratista porque no contiene la escogencia de la mejor propuesta y ii) que se demuestre que, mediante el sometimiento estricto a las normas que rigen la escogencia del contratista, se deduce que el actor hizo la mejor propuesta. (Consejo de Estado, Exp:15963, 2008)

Esta doble cargase evidencia en el sentido de que al tratarse de la acción de nulidad y restablecimiento del derecho, en primer lugar debe existir la comprobación objetiva de ilegalidad del acto que se imputa, por cualquiera de los cargos señalados en el Código de Procedimiento Administrativo y de lo Contencioso Administrativo, o específicamente por sustentarse en una clausula ambigua o anfibológica claramente contradictoria al principio de selección objetiva, y por supuesto, la demostración objetiva de la existencia del perjuicio a un derecho cuyo restablecimiento se exige.

\section{CONCLUSIONES}

Por último, a manera de conclusión y en cuanto a la naturaleza jurídica del pliego y su alcance en la contratación estatal, podemos sostener que es un documento precontractual o previo al contrato en el cual se consignan la reglas que rigen el procedimiento y la selección del contratista, reglas que iluminadas por los principios orientadores de la administración pública y de la contratación estatal, deben ser objetivas y justas, dando de paso la oportunidad de participar en igualdad de condiciones a los posibles oferentes y al cual deberán sujetarse las ofertas (Luna y Nisimblat (2017); motivo por el cual se entiende que existiendo alguna diferencia entre el pliego y el contrato, el primero prevalece sobre el segundo; y que luego de culminar el proceso de selección de contratistas de manera exitosa, muta o se transforma en una cláusula del contrato.

De otra parte, en cuanto a la Responsabilidad de la Administración derivada del acto de adjudicación del contrato, cuando este se fundamenta en cláusulas ambiguas, oscuras, anfibológicas del pliego de condiciones, se sostiene que para la declaración de dicha responsabilidad es necesario que se pruebe que el acto de adjudicación es contrario al ordenamiento que rige la selección del contratista porque no contiene la escogencia de la mejor propuesta y que el actor hizo la mejor propuesta, elementos que resultan indispensables para el correspondiente restablecimiento del derecho.

El actual estatuto contractual expresa e inequívocamente determinó que aquellas estipulaciones contenidas en los pliegos de condiciones o términos de referencia que contravengan las prescripciones contenidas en el art. 24 de la ley 80 de 1993 consagratorio del principio de la transparencia 
“serán ineficaces de pleno derecho", particularmente aquéllas que establezcan reglas de selección por fuera de la objetividad, claridad y justicia que debe manifestarse en los pliegos que gobiernan el proceso de selección, razón por la cual, las cláusulas que adolezcan de tales defectos, deberán ser depuradas el juez en sede de lo contencioso administrativo.

La responsabilidad precontractual derivada de cláusulas oscuras que nutren el acto de adjudicación del contrato es imputable a la administración en virtud del principio de la carga de claridad del pliego de condiciones y los correlativos principios de igualdad, transparencia, selección objetiva y libertad de concurrencia que orientan la actividad precontractual de la administración pública.

\section{REFERENCIAS BIBLIOGRAFICAS}

ARIÑO ORTIZ, Gaspar. “El enigma del contrato administrativo.” En Revista de Administración Pública. No. 172, 2007.

ALVAREZ, A. (Enero- Junio 2012). La Capacidad jurídica de consorcios y uniones temporales en el marco de la contratación estatal. Universidad Libre. Revista VERBA IURIS No. 27.

BECERRA SALAZAR, I. (2008). Los riesgos en la contratación estatal: Estimación, tipificación y asignación. Bogotá D.C.: Leyer.

BENAVIDES RUSSI, J. L., \& SANTOFIMIO GAMBIA, J. O. (2010). X Jornadas de Derecho Administrativo. Incertidumbre en la contratación estatal. Bogotá D.C.: Universidad Externado de Colombia.

BENAVIDES, J. L. (2004). El Contrato Estatal. Entre el derecho publico y el derecho privado. Bogotá D.C.: Universidad Externado de Colombia.

BENAVIDES, J. L. “La reforma de la Ley 80 de 1993: Mucho ruido y pocas nueces”, Revista Digital de Derecho Administrativo. Universidad Externado de Colombia. Bogotá D.C. Vol. 1.

BONIVENTO FERNANDEZ, J. A. (1987). Los principales contratos civiles y su paralelo con los comerciales. Bogotá D.C.: Librería del Pofesional.

Constitución Política de 1.991.

CONSEJO DE ESTADO. Sala de lo Contencioso Administrativo. Sección Tercera. Consejera 
Ponente: Ruth Stella Correa Palacio. Sentencia del 19 de julio de 2.010. Expediente: 33795.

CONSEJO DE ESTADO. Sala de lo Contencioso Administrativo. Sección Tercera. Consejero Ponente: Danilo Rojas Betancourt. Sentencia del 10 de marzo de 2011. Expediente: 15666.

CONSEJO DE ESTADO. Sala de lo Contencioso Administrativo. Sección Tercera. Consejero Ponente: Jaime Orlando Santofimio Gamboa. Sentencia del 2.012.

CONSEJO DE ESTADO. Sala de lo Contencioso Administrativo. Sección Tercera. Sentencia del 04 de diciembre de 2.006. Consejero Ponente: Mauricio Fajardo. Expediente: 32871.

CONSEJO DE ESTADO. Sala de lo Contencioso Administrativo. Sección Tercera. Sentencia del 19 de septiembre de 2.007. Consejero Ponente: Enrique Gil Botero. Expediente: 26649.

CONSEJO DE ESTADO. Sala de lo Contencioso Administrativo. Sección Tercera. Sentencia del 14 de febrero de 2.012. Consejero Ponente: Jaime Orlando Santofimio. Expediente: 38924 (IJ)

CONSEJO DE ESTADO, Sala de lo Contencioso Administrativo, Sección Tercera Sentencia 12037 del 19 de julio de 2.001. Consejero Ponente: Alier Eduardo Hernández Enríquez.

CONSEJO DE ESTADO. Sala de lo Contencioso Administrativo. Sección Tercera. Sentencia 13416 del 29 de enero de 2.004. Consejero Ponente: Alier Eduardo Hernández Enríquez.

CONSEJO DE ESTADO. Sala de lo Contencioso Administrativo. Sección Tercera. Consejero Ponente: Ricardo Hoyos Duque. Sentencia del 7 de junio de 2.001. Exp. 13405.

CONSEJO DE ESTADO. Sala de lo Contencioso Administrativo. Sección Tercera. Sentencia 21077 del 29 de agosto de 2.012. Consejero Ponente: Danilo Rojas Betancourt.

CONSEJO DE ESTADO. Sala de lo Contencioso Administrativo. Sección Tercera. Sentencia del 30 de julio de 2.008. Consejero Ponente: Mauricio Fajardo Gómez. Expediente: 23003.

CONSEJO DE ESTADO. Sala de lo Contencioso Administrativo. Sección Tercera. Sentencia del 10 de marzo de 2.011. Consejero Ponente: Danilo Rojas Betancouth. Expediente: 15666.

CONSEJO DE ESTADO, Sala de lo Contencioso Administrativo, Sección Tercera, Sentencia del 
30 de Mayo de 1.991. Consejero Ponente: Julio Cesar Uribe Acosta. Expediente 3.577.

CONSEJO DE ESTADO, Sección Tercera, de enero 16 de 1975, exp. 1503, M.P. Gabriel Rojas Arbeláez.

CONSEJO DE ESTADO, Sala de lo Contencioso Administrativo. Sección Tercera. Sentencia del 19 de julio de 2.001. Exp. 12037.

CONSEJO DE ESTADO, Sección Tercera, de septiembre 19 de 2007, exp. 26649, Actor: Carolina Arango Uribe, Demandado: Instituto Nacional de Concesiones, M.P. Enrique Gil Botero.

CONSEJO DE ESTADO. Sala de lo Contencioso Administrativo. Sección Tercera. Sentencia del 21 de mayo de 2.008. Exp.15963.

CONSEJO DE ESTADO, Sala de lo Contencioso Administrativo, Sección Tercera, Sentencia proferida el 19 de septiembre de 1994. Expediente 8071;

CONSEJO DE ESTADO. Sala de lo Contencioso Administrativo. Sección Tercera sentencias del 27 de marzo de 1992, expediente 6353.

CONSEJO DE ESTADO. Sala de lo Contencioso Administrativo. Sección Tercera, sentencia del11 de abril de 2002, expediente 12.294.

CONSEJO DE ESTADO. Sala de lo Contencioso Administrativo. Sección Tercera sentencia del 19 de julio de Expediente 12.037;

CONSEJO DE ESTADO. Sala de lo Contencioso Administrativo. Sección Tercera, sentencia11192 proferida el 23 de abril de 1998;

CONSEJO DE ESTADO. Sala de lo Contencioso Administrativo. Sección Tercera, sentencia del 3 de mayo de 1999, Expediente 12.344, CP: Dr. Daniel Suárez Hernández;

CONSEJO DE ESTADO. Sala de lo Contencioso Administrativo. Sección Tercera, sentencia 15.235 del 24 de junio de 2004.

CONSEJO DE ESTADO. Sala de lo Contencioso Administrativo. Sección Tercera, Sentencia de 
27 de noviembre de 2002. Exp. 13.792. Actor: Sociedad Henry Lozada Vélez y Cía Ltda. Demandado: INVICALI.

CONSEJO DE ESTADO. Sala de lo Contencioso Administrativo. Sección Tercera. Sentencia del 23 de abril de 1.998. Consejero Ponente: Daniel Suarez Hernández.

CONSEJO DE ESTADO. Sala de lo Contencioso Administrativo, Sección Tercera. Sentencia Proferida el 24 de junio de 2004.

CONSEJO DE ESTADO. Sala de lo Contencioso Administrativo. Sección Tercera. Sentencia del 21 de mayo de 2.008. Exp.15963.

Corte Constitucional, sentencia C-037 de enero 26 de 2000

Corte Constitucional, Sentencia C-037 de 2000

Corte Constitucional, Sentencia C-1048 de 2001

Corte Constitucional, Sentencia C-712 de 2005.

CARLOS AYMERICH CANO. “Acerca de la naturaleza normativa de los pliegos de cláusulas administrativas particulares".

Decreto 1510 de 2013. Art. 22.

DIEZ, MANUEL MARÍA, Derecho Administrativo T. II, Buenos Aires, Obema 1.993. En ese mismo sentido DROMI, Derecho Administrativo, Buenos Aires, Ciudad Argentina, 1995.

DROMI, J. R. (1977). Licitación Pública. Buenos Aires: Editorial Astrea.

FANDIÑO GALLO, Jorge. “La contratación estatal”, Leyer. 2.014.

ESCOBAR GIL, Rodrigo. Teoría general de los contratos de la administración pública. Bogotá, Legis. 1.999.

ESCOBAR GIL, R. (1999). Teoría General de los contratos de la administración pública. Bogotá 
D.C.: Legis.

ESCOBAR, H. (1977). Tratado integral de los contratos administrativos. Buenos Aires.: Editorial Astrea.

EXPOSITO VELEZ, J. C. (2004). La configuración del contrato de la administración pública en el derecho colombiano y español. Bogotá D.C.: Universidad Externado de Colombia.

EXPOSITO VELEZ, J. C. (s.f.). Forma y contenido del contrato estatal. Bogotá D.C.: Universidad Externado de Colombia.

GARCIA DE ENTERRIA, E., \& FERNANDEZ RODRIGUEZ, T. (1997). Curso de derecho adminisrativo (Vol. I). Madrid: Civitas.

GARCÍA ORTEGA. P. “Manual de Contratos del Estado” Ministerio de Obras Públicas y Urbanismo.

GONZALES LOPEZ, E. (2010). El pliego de condiciones en la contratación estatal. La reforma consagrada en la Ley 1150 de 2007 y sus decretos reglamentarios. Bogotá D.C.: Universidad Externado de Colombia.

GOMEZ LEE, I (2013). El derecho de la contratación pública en Colombia. Análisis y Comentarios al Decreto 1510 de 2013. Bogotá D.C.: Editorial Legis.

Luna, F. y Nisimblat, N. (2017). El Proceso Monitorio. Una innovación judicial para el ejercicio de los derechos crediticios. Revista Mario Alario D’Filippo 9 (17): 154-168. Recuperado de DOI https://doi.org/10.32997/2256-2796-vol.9-num.17-2017-1546

MATALLANA CAMACHO, E. (2013). Manual de Contratación de la Administración Pública. Reforma de la ley 80 de 1993. Bogotá D.C.: Universidad Externado de Colombia.

MARÍN HERNÁNDEZ, HUGO. "Naturaleza jurídica de las facultades de la administración para confeccionar pliegos de condiciones" en Revista Digital de Derecho Administrativo No. 1, primer semestre de 2.009 , en línea.

PARADA VAZQUES, RAMÓN. Derecho Administrativo, T. I, Madrid, Marcial Pons, 1.995; 
SANTAMARÍA PASTOR, JUAN ALFONSO. Principios de derecho administrativo, Madrid, Centro de Estudios Ramón Areces, 1.994.

SOSA WAGNER, FRANCISCO (Coor). El derecho administrativo en el umbral del siglo XXI, homenaje al profesor D. RAMÓN MARTíN MATEO, t. I, Madrid, Tirant Lo Blanch, 2.000.

Ley 80 de 1993, Congreso de la República

Ley 1150 de 2007, Congreso de la República. 